\title{
Mesh-Grounded Monopolar Hexagonal Microstrip Antenna for Artillery-Launched Observation Round
}

\author{
Dongho Lee ${ }^{1} \oplus$, Kichul $\mathrm{Kim}^{2}$ and Seongmin Pyo ${ }^{3, *} \mathbb{0}$ \\ 1 Department of Automatic Electric Engineering, Yeungnam University College, Daegu 42415, Korea; \\ dongho@ync.ac.kr \\ 2 The Second Research and Development Institute, Agency for Defense Development, Daejeon 34186, Korea; \\ kimkc@add.re.kr \\ 3 Department of Information and Communication Engineering, Hanbat National University, \\ Daejeon 34158, Korea \\ * Correspondence: spyo@hanbat.ac.kr; Tel.: +82-42-821-1202
}

Received: 8 October 2019; Accepted: 1 November 2019; Published: 3 November 2019

check for updates

\begin{abstract}
This paper presents a novel low-profile microstrip antenna with an omnidirectional radiation pattern for an artillery-launched observation round. The proposed antenna consists of one centered hexagonal patch for a feeding network and six periodic arrays of a trapezoid patch for a radiator. The trapezoid patch is equal to a half-sized hexagonal patch based on geometrical symmetry. A gap-coupled one-hexagonal patch and six trapezoid patches are supported on a nonfundamental $\mathrm{TM}_{02}$ mode for vertically polarized omnidirectional radiation patterns. In addition, a meshed ground structure for the proposed antenna is employed to improve the impedance bandwidth. The thin metal wires that are formed by the meshed ground structure yield six trapezoid slot arrays for the feeding network and three triangular slot arrays for the radiator on the ground plane. To verify the feasibility of the meshed ground structure, the mesh width, denoted by $w$, was investigated theoretically and optimized carefully to enlarge the impedance bandwidth of the proposed antenna. Finally, the proposed antenna, with a mesh width of $0.2 \mathrm{~mm}$, successfully demonstrated excellent monopolar radiation at a resonant frequency of $5.84 \mathrm{GHz}$, a realized gain of $5.27 \mathrm{dBi}$, and an impedance bandwidth of $452 \mathrm{MHz}$ from $5.583 \mathrm{GHz}$ to $6.035 \mathrm{GHz}$ with respect to $7.78 \%$ at a center frequency of $5.809 \mathrm{GHz}$.
\end{abstract}

Keywords: hexagonal microstrip antenna; monopolar radiation; omnidirectional pattern; gap-coupling resonator array; mesh ground

\section{Introduction}

With the rapid development of recent wireless systems, such as radio frequency identification (RFID), Bluetooth, and WLAN, microstrip antennas have been mainly utilized as key components because of their many advantages, such as their light weight, low manufacturing cost, relatively small size, and ease of system integration [1-3]. In particular, the microstrip-inspired monopole antenna for ultrawideband (UWB) application is very useful for stationary communication networking due to its omnidirectional radiation pattern and boresight direction radiation with about $120^{\circ}$ of half-power beam width (HPBW) [4-9]. The microstrip-based monopole antenna, however, shows a disadvantage in that it increases the surface drag yield from a terminal moving at high speed because of its mounting direction being perpendicular to the ground surface.

For this reason, a monopolar microstrip antenna, that is, a low-profile antenna placed horizontally to the ground surface with an omnidirectional radiation pattern, has been spotlighted as a suitable candidate for wireless access in vehicular environments (WAVE) or in cooperative unmanned aerial 
vehicle (UAV) networks because no additional radome structures are needed and because surface drag yield from fast-moving objects can be minimized [10,11]. Since the introduction of monopolar microstrip antennas in 1994 [12], various monopolar microstrip antennas have been presented based on the design method of a center-fed circular microstrip patch antenna to realize a nonfundamental resonant mode using more than one wavelength-sized radiator [13-15] and zeroth-order resonant antennas with an infinite wavelength resonant mode [16-19].

In this work, we propose a new monopolar hexagonal microstrip antenna with a mesh ground structure for mounting a deployable wing of an artillery-lunched observation round. To overcome the large electrical radiator size of the center-fed microstrip antenna and the narrow bandwidth of the zeroth-order resonant antenna, the proposed antenna utilizes a regular hexagonal radiator with a trapezoidal patch resonator arranged on a mesh ground structure. Unlike conventional honeycomb or mushroom structures [19], the nonfundamental $\mathrm{TM}_{02}$ mode was realized by cutting the mesh-grounded hexagonal patch without a thru-hole via fabrication. Accordingly, the proposed antenna can show a relatively wide bandwidth and an electrically small size at the same time (compared to previously presented technologies of center-fed microstrip antennas and zeroth-order resonant antennas). In addition, a parametric study of the thin line width caused by the mesh ground structure was carried out to verify the feasibility of the proposed antenna. Details on the configuration and an analysis of the reflection coefficients, resonant frequencies, 3-dB fractional bandwidths, electric field distribution, radiation patterns, realized antenna gain, and quality factors ( $Q$-factors) of the proposed antenna are dealt with in the following sections.

\section{Antenna Design and Analysis}

\subsection{Configuration}

Figure 1 shows the configuration of the proposed antenna. The proposed antenna employed seven patch resonators. The proposed antenna structure consists of one centered hexagonal patch for a feeding network (indicated by the blue dotted line) and six periodic arrays of a trapezoid patch for a radiator (indicated by the red dotted line). In the feeding network, the hexagonal patch is utilized to excite equivalent gap couplings to six radiating resonators and is connected through a 50-ohm coaxial cable from the ground plane. To provide soldering space in the ground plane, six ground slots with a trapezoidal shape were formed at the bottom of the hexagonal feeding patch. The radiating trapezoid patches were constructed in a half-cut using the geometrical symmetry of the feeding hexagonal patch.

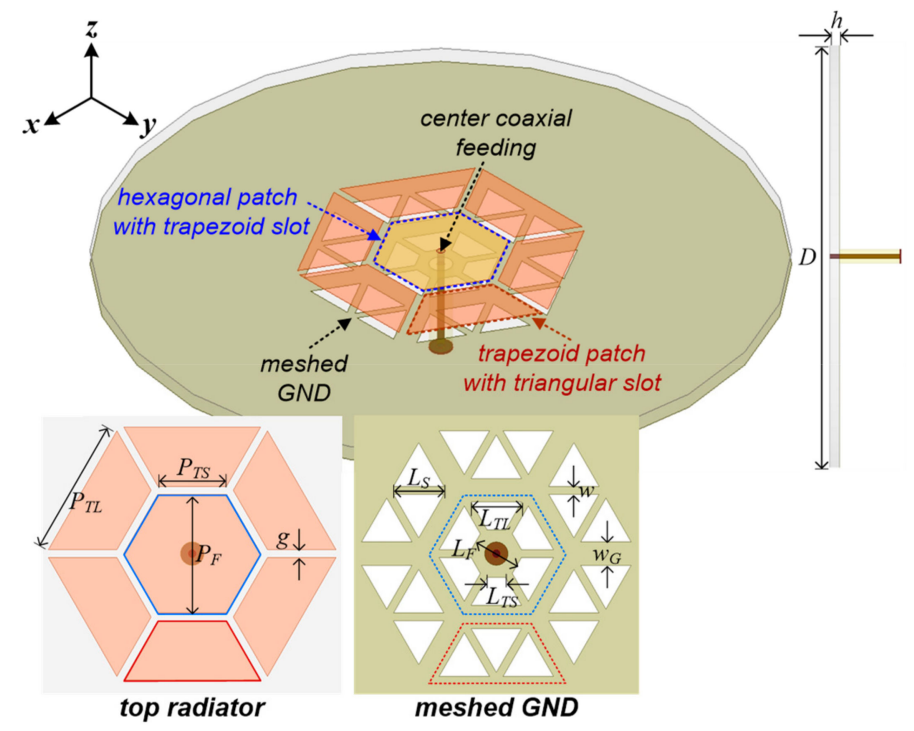

Figure 1. The proposed antenna with a cross-sectional view, an enlarged top radiator, and a bottom mesh ground view. 
It can be seen that the shape of the ground slot forms an equilateral triangle, since the radiating trapezoid patch does not need soldering space. The thin metal wires that are formed by the meshed ground structure yield six trapezoid slot arrays for the feeding network and three triangular slot arrays for the radiator on the ground plane. The width of the thin ground wires (denoted by $w$ ) between slots decreases gradually when the size of the ground slot increases. The coupling gap between patches is denoted by $g$. The thin metal line $w$ (in three directions) is connected to the outer ground, so that three equilateral triangular slots with length $L_{S}$ are created at the bottom of the patch. Finally, by quasi-circularly arranging six radiator trapezoidal patches, the final geometry is the gap-coupled hexagonal microstrip antenna. A 70-mm-diameter $(D)$ and 1.6-mm-thick $(h)$ FR4 circular substrate is used, and it also has a dielectric constant of 4.25 and a loss tangent of 0.018 . The substrate of the proposed antenna was determined by considering mechanical limiting factors and the cost factors for the observation round-system requirement. All dimensions of the gaps and the minimum widths between the resonators are $0.2 \mathrm{~mm}$ to ensure process reliability. In addition, the inside of each radiating patch has an isolation area the same size as the wire width. The final parameters of the proposed antenna were optimized using an FEM(finite element method)-based full-wave EM (electromagnetic) simulator and are summarized in Table 1.

Table 1. Optimized dimensions of the proposed antenna.

\begin{tabular}{cccc}
\hline Parameters & Size $(\mathbf{m m})$ & Parameters & Size $(\mathbf{m m})$ \\
\hline Feed patch length $\left(P_{F}\right)$ & 13 & GND(Ground) gap mesh width $\left(w_{g}\right)$ & 0.6 \\
Radiator upper length $\left(P_{T S}\right)$ & 7.5 & GND slot length $\left(L_{S}\right)$ & 7.0 \\
Radiator lower length $\left(P_{T L}\right)$ & 15 & GND pad length $\left(L_{F}\right)$ & 4.5 \\
Gap between patches $(g)$ & 0.2 & GND feed slot upper length $\left(L_{T S}\right)$ & 2.4 \\
GND mesh width $(w)$ & 0.2 & GND feed slot lower length $\left(L_{T L}\right)$ & 4.5 \\
Substrate diameter $(D)$ & 70 & Substrate thickness $(h)$ & 1.6 \\
\hline
\end{tabular}

\subsection{Design Principle and Field Distribution}

Figure 2 illustrates the simulated electric field distributions for an understanding of the design procedure and operation principles of the proposed antenna. The conventional hexagonal mushroom structure that is commonly utilized for electromagnetic metamaterial applications [16] or high impedance planes [20] provides dual-band operation for the zeroth-order resonant (ZOR) and $\mathrm{TM}_{02}$ modes (shown in the left side of Figure 2).
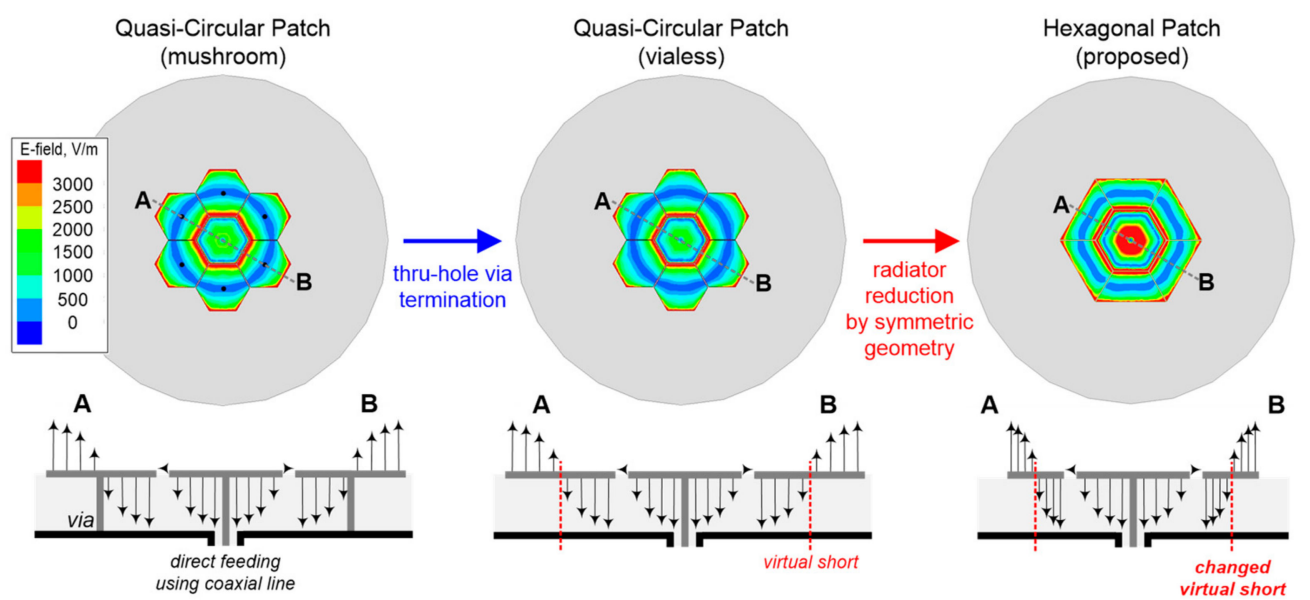

Figure 2. Concept with simulated electric field distributions for the $\mathrm{TM}_{02}$ mode and their electric field vector magnitudes in a cut-plane of A-B.

As expected, the ZOR mode yields parallel resonance from the shunt inductance (caused by the thru-via hole) and the shunt capacitance between the patch metal and mesh ground metal [19]. 
In addition, the hexagonal patch also supports the fundamental mode, that is, the half-wavelength resonant mode of the $\mathrm{TM}_{01}$ mode, and thus the linearly arranged three hexagonal patches can make an over-wavelength $\mathrm{TM}_{02}$ mode for omnidirectional radiation. As shown in the middle of Figure 2, the via-removed hexagonal mushroom resonator only gives a $\mathrm{TM}_{02}$ mode. As shown on the right side of Figure 2, we finally reduced the hexagonal radiating patch to the trapezoidal radiating patch, that is, the linearly tapered radiating patch. This cutting design using geometrical symmetry provides the advantages of an enlarged bandwidth and a miniaturized size of the radiating patches compared to the conventional hexagonal patches. The simulated results for the comparisons in Figure 2 are shown in Figure 3. Accordingly, the proposed antenna can accomplish a successful $\mathrm{TM}_{02}$ mode for omnidirectional radiation.

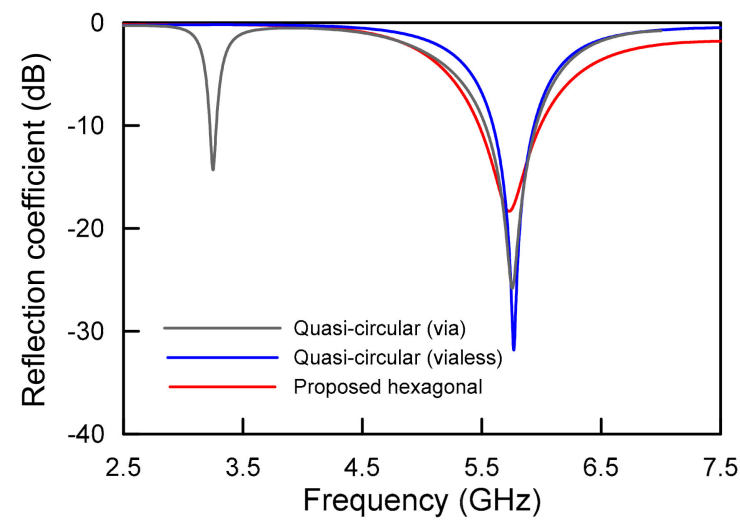

Figure 3. Reflection coefficient comparison of the three kinds of antenna design in Figure 2.

\section{Measurement Results}

To verify the design feasibility, a proposed antenna prototype was fabricated, as shown in Figure 4. The fabricated prototype had the dimensions in Table 1 for the meshed ground structure. The meshed ground structure was successfully implemented as shown in Figure $4 \mathrm{~b}$. After etching the proposed antenna, a commercial semirigid standard coaxial cable with a length of $7 \mathrm{~mm}$ was mounted.

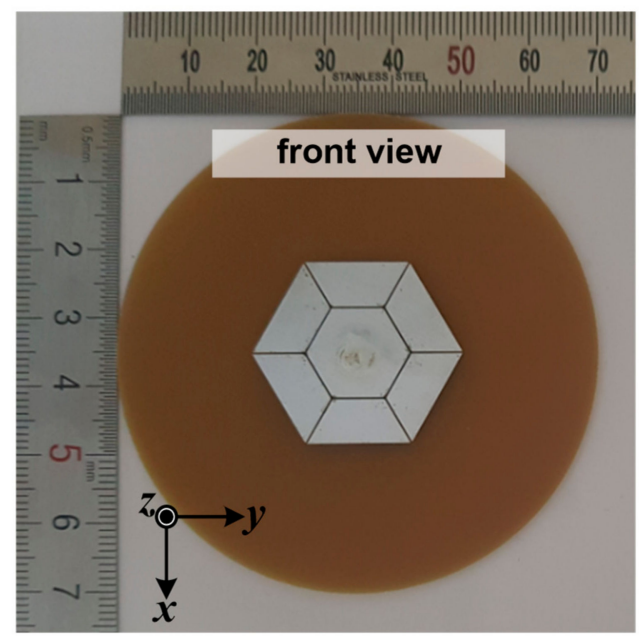

(a)

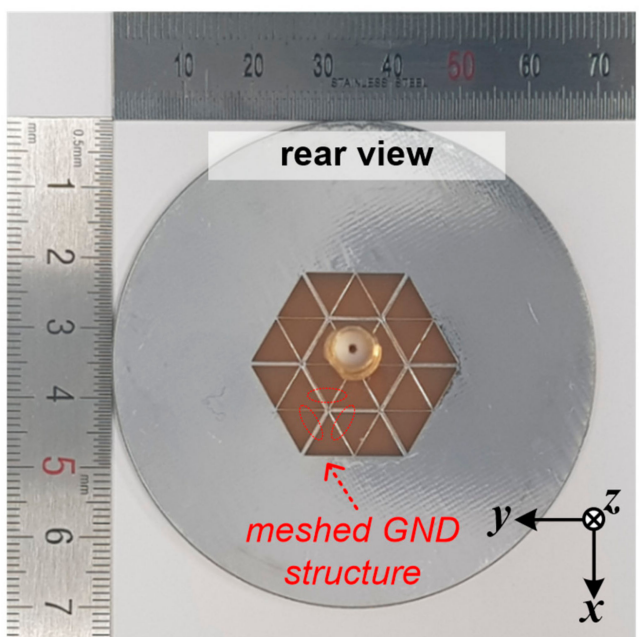

(b)

Figure 4. The fabricated antenna prototype: (a) front view and (b) rear view.

Figure 5 displays the reflection coefficients of the proposed antenna. The measurement results of the fabricated prototype agreed well with the simulations for the proposed antenna. For the simulation, the results were observed at $533 \mathrm{MHz}$ from $5.573 \mathrm{GHz}$ to $6.106 \mathrm{GHz}$ with respect to about $9.13 \%$ at 
a center frequency of $5.840 \mathrm{GHz}$. The measurements were taken according to the 10-dB impedance bandwidths of $452 \mathrm{MHz}$ from $5.583 \mathrm{GHz}$ to $6.035 \mathrm{GHz}$ with respect to about $7.78 \%$ at a center frequency of $5.809 \mathrm{GHz}$ for the $\mathrm{TM}_{02}$ mode. The slight gap between the simulations and measurements was the result of inexact alignment between the top patch plane and the bottom mesh ground surfaces during the process.

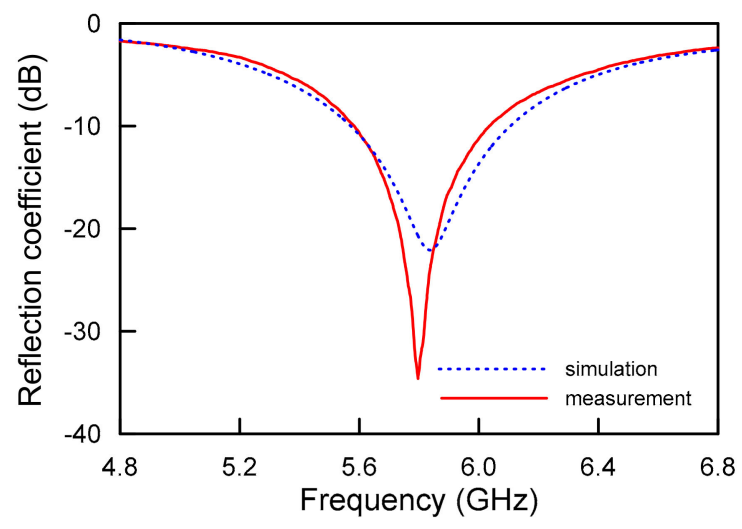

Figure 5. Coefficients of the proposed antenna.

Figure 6 exhibits the far-field radiation patterns of the proposed antenna. The radiation patterns were measured at test frequencies of $5.84 \mathrm{GHz}$ supported by maximum antenna-realized gains. The radiation patterns were measured in a well-defined and calibrated electromagnetic anechoic chamber consisting of room space $5.5 \mathrm{~m}$ in width, $5.5 \mathrm{~m}$ in length, and $5 \mathrm{~m}$ in height. The anechoic chamber guaranteed the capability to directly measure far-field conditions from $800 \mathrm{MHz}$ to $8 \mathrm{GHz}$. The measurements demonstrated omnidirectional (i.e., monopolar) radiation with copolarization of the vertical linear polarization in the $\mathrm{TM}_{02}$ mode, as shown in Figure 6 . As expected, the proposed antenna was identical to a monopole antenna mounted vertically with a radiation pattern and polarization. The measured peak gains were observed at $\theta=30^{\circ}$, as shown in Figure $6 \mathrm{~b}$.

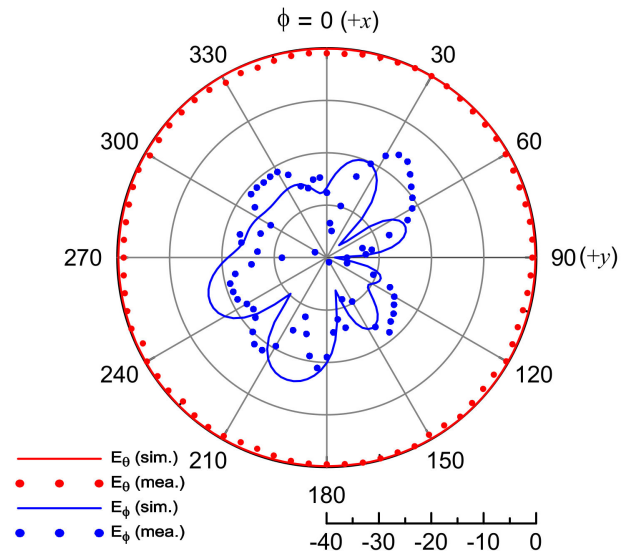

(a)

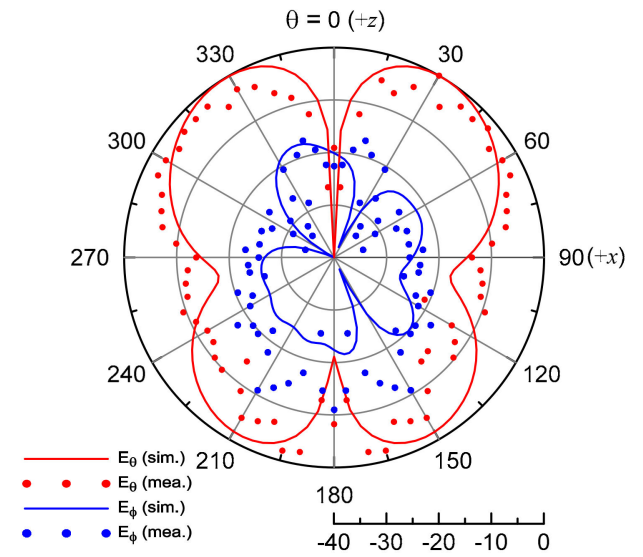

(b)

Figure 6. Radiation patterns of the proposed antenna at a resonant frequency of $5.84 \mathrm{GHz}$ : the (a) $H$-plane ( $x-o-y$ plane) and (b) E-plane ( $z-0-x$ plane).

At a test frequency of $5.84 \mathrm{GHz}$, the directivity of the proposed antenna was different from that of an ideal monopole (that is, an electrically small antenna) due to the radiator at a wavelength of 1.5. At $\theta=30^{\circ}$ in Figure $6 \mathrm{~b}$, the horizontal polarization $\left(E_{\phi}\right)$, that is, the cross-polarization of the proposed antenna, was observed at $-20.64 \mathrm{~dB}$ with a normalized radiation pattern. 
Figure 7 shows the realized antenna gains and radiation efficiencies of the proposed antenna. The realized antenna gains were measured at $5.27 \mathrm{dBi}$ and $5.84 \mathrm{GHz}$ in 1.5 -wavelength resonant $\mathrm{TM}_{02}$ mode. For the simulations, the realized antenna gain was $4.53 \mathrm{dBi}$ at $5.88 \mathrm{GHz}$. As expected, the measurement antenna gains were almost identical to the simulations for the $\mathrm{TM}_{02}$ mode. The reason for the difference between the simulation and measurement experiments of the antenna gain around $6 \mathrm{GHz}$ seemed to be due to the additional losses of the 50-ohm coaxial cable used as the feed line. As shown in Figure $2 b$, it can be seen that the simulation results of the radiation efficiency remained constant at $85.47 \%$. On the other hand, the measurement results of the radiation efficiency showed variation between the maximum value of $90.61 \%$ and the minimum value of $75.69 \%$ (according to the frequency). The deviation between the simulation and measurement results was a reasonable value within the calibration error range that occurs in the anechoic chamber.

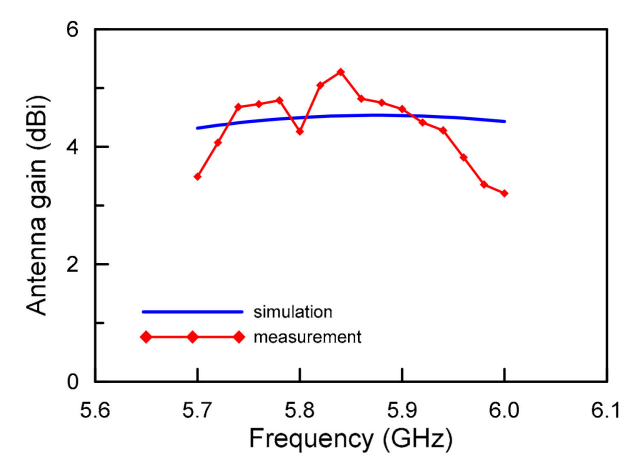

(a)

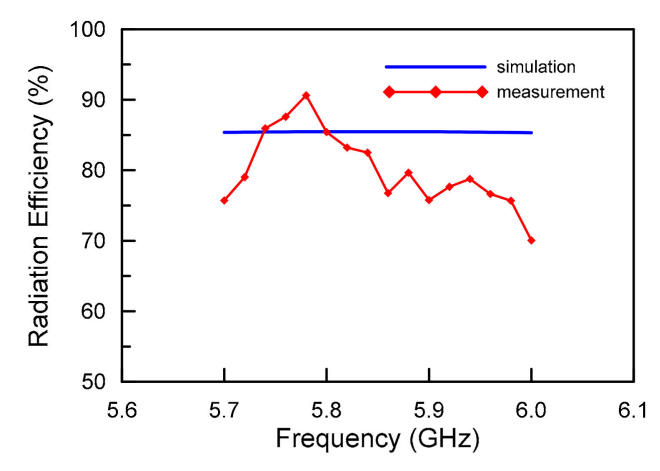

(b)

Figure 7. Measurement results of the proposed antenna: the (a) realized antenna gain and the (b) radiation efficiency.

As seen in the results in Figures 5-7, the proposed antenna successfully demonstrated omnidirectional radiation in the simulation results. A detailed consideration of the performance of the proposed antenna will be given in the following section.

\section{Discussion}

Figure 8 shows the simulation results from the parametric study of the reflection coefficient change for various parameters of the proposed antenna. As can be seen in Figure 8a, as the size of the hexagonal patch used for the feeding network increased, the resonant frequency of the proposed antenna decreased. The cause of this result was that the length of one side of the hexagonal feeding patch was equivalent to the top of the trapezoidal radiator patch. In other words, as the size of the trapezoidal radiator increased, the guided wavelength increased electrically due to the $\mathrm{TM}_{02}$ mode of the boundary condition (which is determined by the trapezoidal radiator patch) increasing. 


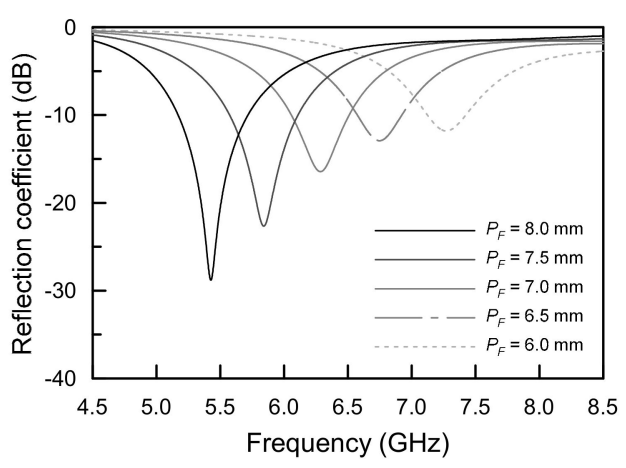

(a)

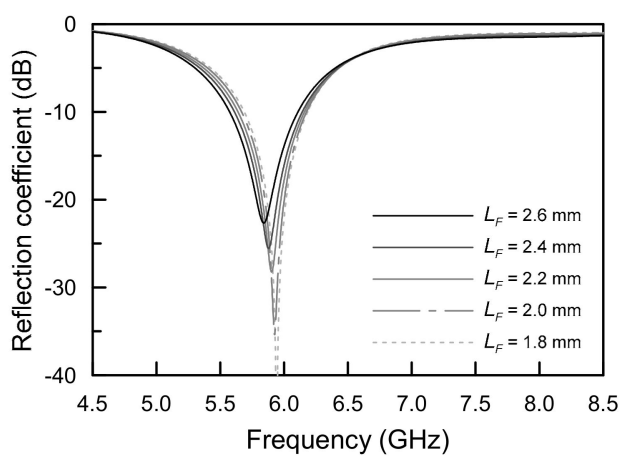

(c)

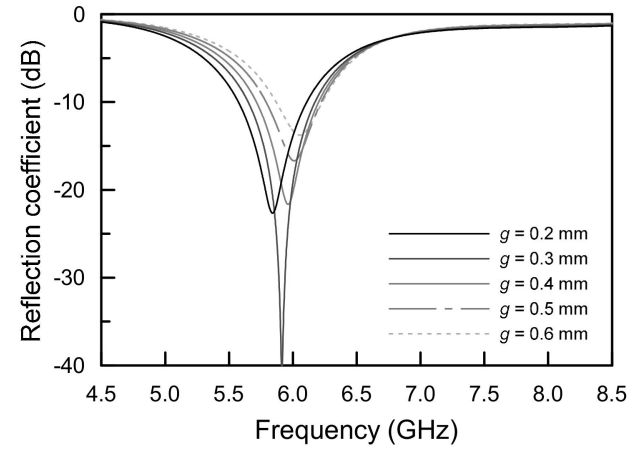

(b)

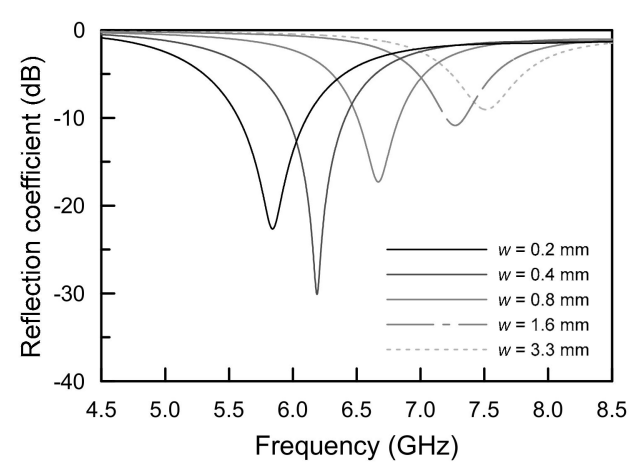

(d)

Figure 8. Reflection coefficients of the proposed antenna from the parametric study: (a) the feeding patch size, (b) gaps between the feeding patch and radiator patch, (c) the ground feed pad space, and (d) the width of the meshed ground.

Figure $8 \mathrm{~b}$ exhibits the change in the reflection coefficients of the proposed antenna when the gap size of $g$ between each patch varied from $0.2 \mathrm{~mm}$ to $0.6 \mathrm{~mm}$. Since the gap $g$ generates coupling between patches, it can be seen that the amount of electrical coupling varied with the gap size of $g$. Therefore, if the operating frequency is determined through the proposed antenna radiator and feeding patch of $P_{F}$, the gap $g$ should be optimized to generate the maximum coupling coefficient.

Figure $8 \mathrm{c}$ displays the results from analyzing the effect of the feeding space for the coaxial connection on the bottom ground plane. As can be inferred from the results, it can be seen that $L_{F}$, the size of the feeding pad, affected the impedance of the proposed antenna and consequently served as a matching network of the proposed antenna. Therefore, $L_{F}$ could determine the optimal impedance of the proposed antenna to expand the 10-dB impedance bandwidth based on the size of the space beyond the 50-ohm coaxial line. Finally, Figure 8d shows the variation of the reflection coefficients for the width change of the thin metal wire caused by the mesh ground structure of the proposed antenna. As the size of the triangular and trapezoidal slots $\left(L_{S}, L_{T S}\right.$, and $\left.L_{T L}\right)$ on the bottom ground plane of the radiator and feeding patch increased, the mesh ground widths, $w$ and $w_{G}$, became thinner. The thinner mesh width could reduce the resonant frequency and increase the impedance bandwidth of the proposed antenna.

Figure 9 shows a quantitative analysis of the electrical properties to verify the feasibility of the mesh ground structure at $w$ variation from $0.2 \mathrm{~mm}$ to $3.3 \mathrm{~mm}$. The limitation of $w=0.2 \mathrm{~mm}$ was the minimum width to ensure process reliability, and $w=3.3 \mathrm{~mm}$ was the maximum width to make the mesh ground structure equivalent to the normal ground of the proposed antenna. As $w$ became thinner from $3.3 \mathrm{~mm}$ to $0.2 \mathrm{~mm}$, the resonance frequency decreased by $1657 \mathrm{MHz}$ from $7.546 \mathrm{GHz}$ to 5.889 $\mathrm{GHz}$, as shown in Figure 9a. This resulted in the same effect as the size reduction rate of about 22\%. 
For a $w$ of $3.3 \mathrm{~mm}$, the 3-dB impedance bandwidth was $949 \mathrm{MHz}$ from $7.071 \mathrm{GHz}$ to $8.020 \mathrm{GHz}$, with a $3-\mathrm{dB}$ fractional bandwidth of about $12.58 \%$ based on the center frequency. In addition, for a $w$ of $0.2 \mathrm{~mm}$, the 3-dB impedance bandwidth was $1613 \mathrm{MHz}$ from $5.082 \mathrm{GHz}$ to $6.695 \mathrm{GHz}$, with a 3-dB fractional bandwidth of $27.39 \%$ at the center frequency.

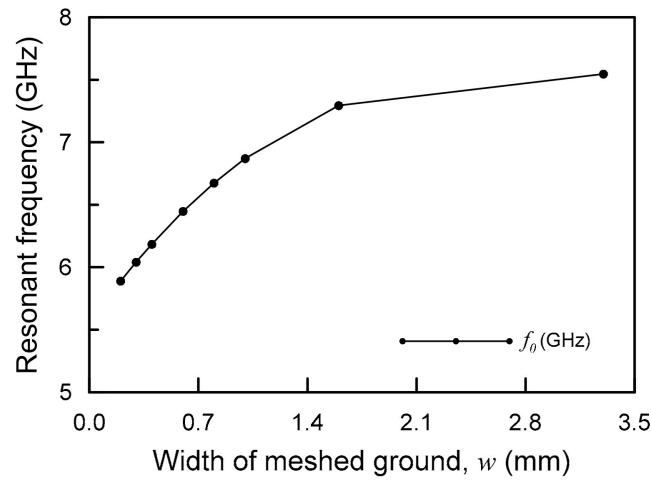

(a)

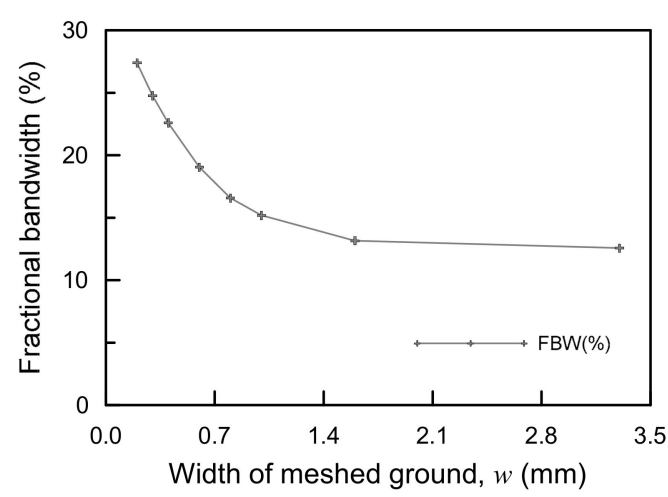

(b)

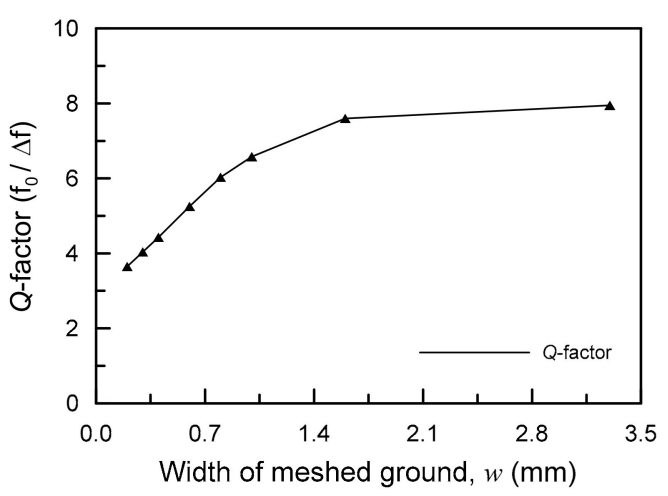

(c)

Figure 9. Characteristics of the proposed antenna with $w$ variation from $0.2 \mathrm{~mm}$ to $3.3 \mathrm{~mm}$ : (a) resonant frequencies, (b) 3-dB fractional bandwidth, and (c) quality factors ( $Q$-factors).

Accordingly, when $w$ changed from $3.3 \mathrm{~mm}$ to $0.2 \mathrm{~mm}$, the $Q$-factor calculated by the ratio of increased 3-dB fractional impedance bandwidth and reduced resonant frequency went from 7.95 to 3.65. In other words, the $Q$-factor of the proposed antenna with the mesh ground structure was reduced by $54 \%$ compared to normal ground, and an effect of about $2.67 \mathrm{~dB}$ was obtained, as shown in Figure 9c. As a result, the $Q$-factor of the proposed antenna was reduced by the decreasing $w$, and the electrical performance (such as the 10- $\mathrm{dB}$ impedance bandwidth) of the proposed antenna was greatly improved due to the meshed ground structure.

The result of this discussion is that, unlike the conventional monopole antenna, the $Q$-factor of the proposed antenna can be reduced by optimizing the meshed ground structure due to the shape of the structurally low-profile omnidirectional antenna.

Several reported microstrip-based omnidirectional antennas and the presented designs are summarized in Table 2 for comparison. The ultrawideband microstrip or CPW-based monopole antennas in References [21-23] showed omnidirectional radiation patterns at a lower frequency of around $3 \mathrm{GHz}$ due to electrically small antennas in those bands and large impedance bandwidths of over $100 \%$. Since the omnidirectional radiation pattern of microstrip-based monopole antennas proceeds in the boresight direction, the radiator should be positioned perpendicularly to the common earth ground surface. Thus, an omnidirectional radiation pattern cannot be provided at the antenna mounting position parallel to the earth's surface, such as with the proposed antenna. The monopolar patch 
antennas recently reported in References [10,24-26] were based on a center-fed $\mathrm{TM}_{02}$ mode operation; thus, the omnidirectional radiation patterns were given in an end-fire direction with the radiator positioned horizontally to the earth ground surfaces. However, the antennas presented earlier showed a relatively thick substrate thickness compared to the proposed antenna. Finally, monopolar radiation based on the electromagnetic metamaterials in Reference [19] has a disadvantage in that it operates only in a narrow bandwidth under conditions of size and thickness of the substrate that are similar to the proposed antenna. Accordingly, the proposed antenna is novel for its reasonable operation bandwidth and relatively thin substrate thickness. These advantages are due to the generation of a $\mathrm{TM}_{02}$ mode in an isotropic array of via-less mushroom structures with meshed GND(Ground) structures.

Table 2. Performance comparisons between state-of-the-art omnidirectional microstrip antennas.

\begin{tabular}{|c|c|c|c|c|}
\hline Ref., Year & Antenna Size, $\mathrm{mm}^{2}\left(/ \lambda_{\min }{ }^{1}\right)$ & Height, $\operatorname{mm}\left(/ \lambda_{\min }{ }^{1}\right)$ & Bandwidth (\%) & Antenna Type \\
\hline [21], 2011 & $22(0.227) \times 28(0.289)$ & $1(0.010)$ & $117 \%$ & $\begin{array}{l}\text { Ultrawideband } \\
\text { monopole }\end{array}$ \\
\hline [22], 2014 & $19(0.190) \times 19(0.190)$ & $1(0.010)$ & 133\% (VSWR < 2) & $\begin{array}{l}\text { Ultrawideband } \\
\text { monopole }\end{array}$ \\
\hline [23], 2015 & $25(0.263) \times 25(0.263)$ & $1.6(0.017)$ & $143 \%($ VSWR < 2) & $\begin{array}{l}\text { Ultrawideband } \\
\text { monopole }\end{array}$ \\
\hline [10], 2016 & $\pi \times 32(0.514) \times 32(0.514)$ & $3(0.048)$ & $32.2 \%$ & $\begin{array}{l}\text { Monopolar } \\
\text { microstrip }\end{array}$ \\
\hline [24], 2016 & $\pi \times 30.8(0.572) \times 30.8(0.572)$ & $6.3(0.117)$ & $15.4 \%$ & $\begin{array}{l}\text { Monopolar } \\
\text { microstrip }\end{array}$ \\
\hline [25], 2016 & $80(0.213) \times 80(0.213)$ & $26(0.069)$ & $96.8 \%$ & $\begin{array}{l}\text { Monopolar } \\
\text { microstrip }\end{array}$ \\
\hline [26], 2019 & $\pi \times 80(0.987) \times 80(0.987)$ & $10(0.123)$ & $12.7 \%$ & $\begin{array}{l}\text { Monopolar } \\
\text { microstrip }\end{array}$ \\
\hline [19], 2009 & $35(0.502) \times 35(0.502)$ & $0.76(0.011)$ & $0.7 \%$ & $\begin{array}{l}\text { Zeroth-order } \\
\text { resonant }\end{array}$ \\
\hline This Work & $\pi \times 35(0.651) \times 35(0.651)$ & $1.6(0.030)$ & $7.78 \%$ & $\begin{array}{l}\text { Monopolar } \\
\text { microstrip }\end{array}$ \\
\hline
\end{tabular}

${ }^{1} \lambda_{\min }$ is the free-space wavelength at the lowest operating frequency of the overlapped bandwidth.

Figure 10 illustrates the 10-dB impedance bandwidths and realized gains of the proposed antenna when changing the substrate diameter of $D$ from $50 \mathrm{~mm}$ to $80 \mathrm{~mm}$. The total antenna size calculated from $\pi(0.5 D)^{2}$ mainly impacts the impedance bandwidths and realized antenna gains of the proposed antenna. In the parametric study about the $D$ of the proposed antenna, there was a large impedance mismatch below $50 \mathrm{~mm}$ of the $D$, and the 10-dB impedance bandwidths were only considered for over $50 \mathrm{~mm}$ of $D$. As the $D$ changed, the 10-dB impedance bandwidth and realized antenna gain varied with the maximum values. The 10- $\mathrm{dB}$ impedance bandwidth was at a maximum when the $D=65 \mathrm{~mm}$, and the realized antenna gain was at a maximum when the $D=75 \mathrm{~mm}$. Accordingly, it can be seen that the proposed antenna prototype was fabricated at the optimal point $(D=70 \mathrm{~mm})$ for both the antenna gain and impedance bandwidth. This is the finite ground effect: traditional monopole antennas are affected by antenna gain and reflection coefficients depending on the finite ground plane size. This is due to the identical directions of the electric fields and operation mechanisms of both monopolar microstrips and conventional monopole antennas. 


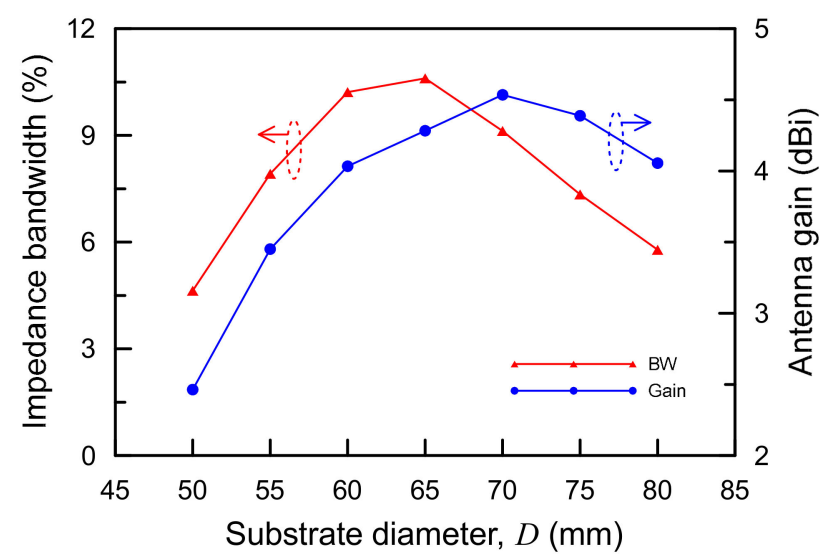

Figure 10. 10-dB impedance bandwidth and realized antenna gains of the proposed antenna with a substrate diameter of $D$ variation from $50 \mathrm{~mm}$ to $80 \mathrm{~mm}$.

\section{Conclusions}

In this paper, a novel low-profile monopolar microstrip antenna was uniquely designed, analyzed carefully, tested, and demonstrated successfully. The proposed antenna design is comprised of a center-fed and gap-coupled hexagonal microstrip antenna on the bottom-meshed ground structure of a circular dielectric substrate. Through control of the $Q$-factor of the proposed antenna diodes (by optimizing a meshed ground structure), the impedance bandwidth in $\mathrm{TM}_{02}$ mode operation is effectively improved by up to $452 \mathrm{MHz}(7.78 \%)$ for measurement and $533 \mathrm{MHz}(9.13 \%)$ for simulation. The $Q$-factor was also investigated based on a parametric study of the line width $w$ of the meshed ground changing from $3.3 \mathrm{~mm}$ to $0.2 \mathrm{~mm}$. The measured results showed good agreement with the simulated responses, thereby validating the proposed design concept and the feasibility of the meshed ground. The geometry can be further exploited to enhance the electrical characteristics of the low-profile monopolar radiating antenna element. Finally, the proposed antenna may be a suitable future military application for observation rounds of fast-moving objects without increasing surface drag.

Author Contributions: Conceptualization, D.L., K.K., and S.P.; methodology, investigation, resources, and data curation, D.L. and S.P.; writing-D.L. and S.P.; supervision, K.K. and S.P.; funding acquisition, K.K. and S.P.

Funding: This work was supported by the Agency for Defense Development (ADD) under Grant UD170085ED and in part by the Basic Science Research Program through the National Research Foundation of Korea (NRF) funded by the Ministry of Education (2016R1D1A1B04932071).

Conflicts of Interest: The authors declare no conflict of interest.

\section{References}

1. James, J.R.; Hall, P.S.; Wood, C. Microstrip Antenna Theory and Design, Vol. 1; Peter Peregrinus: London, UK, 1981.

2. Garg, R.; Bahl, P.; Ittipiboon, A. Microstrip Antenna Design Handbook; Artech House: Dedham, MA, USA, 2001.

3. Zaid, J.; Abdulhadi, A.E.; Denidni, T.A. Miniaturized Multi-Port Microstrip Patch Antenna Using Metamaterial for Passive UHF RFID-Tag Sensor Applications. Sensors 2019, 19, 1982. [CrossRef] [PubMed]

4. Ojaroudi Parchin, N.; Jahanbakhsh Basherlou, H.; Al-Yasir, Y.; Abd-Alhameed, R.; Abdulkhaleq, A.; Noras, J. Recent Developments of Reconfigurable Antennas for Current and Future Wireless Communication Systems. Electronics 2019, 8, 128. [CrossRef]

5. Hasan, M.; Rahman, M.; Faruque, M.; Islam, M.; Khandaker, M. Electrically Compact SRR-Loaded Metamaterial Inspired Quad Band Antenna for Bluetooth/WiFi/WLAN/WiMAX System. Electronics 2019, 8 , 790. [CrossRef]

6. Rahman, M.; Faruque, M.; Ahamed, E.; Islam, M.; Singh, M. Nickel Particle-Based Compact Flexible Antenna for Modern Communication Systems. Electronics 2019, 8, 787. [CrossRef] 
7. Khan, T.; Rahman, M.; Akram, A.; Amin, Y.; Tenhunen, H. A Low-Cost CPW-Fed Multiband Frequency Reconfigurable Antenna for Wireless Applications. Electronics 2019, 8, 900. [CrossRef]

8. Rahman, M.; Park, J. The Smallest Form Factor UWB Antenna with Quintuple Rejection Bands for IoT Applications Utilizing RSRR and RCSRR. Sensors 2018, 18, 911. [CrossRef]

9. Iqbal, A.; Smida, A.; Mallat, N.; Islam, M.; Kim, S. A Compact UWB Antenna with Independently Controllable Notch Bands. Sensors 2019, 19, 1411. [CrossRef]

10. Wong, H.; So, K.K.; Gao, X. Bandwidth Enhancement of a Monopolar Patch Antenna with V-Shaped Slot for Car-to-Car and WLAN Communications. IEEE Trans. Veh. Technol. 2016, 65, 1130-1136. [CrossRef]

11. Yoon, S.; Tak, J.; Choi, J.; Park, Y.M. Conformal Monopolar Antenna for UAV Applications. In Proceedings of the 2017 IEEE Int'1 Symposium on Antennas and Propagation \& USNC/URSI Nat'1 Radio Science Meeting, San Diego, CA, USA, 9-14 July 2017; pp. 517-518. [CrossRef]

12. Burberry, B.A.; Foster, P.R. New Kind of Microstrip Antenna: The Monopolar Wire Patch Antenna. Electron. Lett. 1994, 30, 745. [CrossRef]

13. Al-Zoubi, A.; Yang, F.; Kishk, A. A Broadband Center-Fed Circular Patch-Ring Antenna with a Monopole Like Radiation Pattern. IEEE Trans. Antennas Propag. 2009, 57, 789-792. [CrossRef]

14. Liu, J.; Xue, Q.; Wong, H.; Lai, H.W.; Long, Y. Design and Analysis of a Low-Profile and Broadband Microstrip Monopolar Patch Antenna. IEEE Trans. Antennas Propag. 2013, 61, 11-18. [CrossRef]

15. Liu, J.; Zheng, S.; Li, Y.; Long, Y. Broadband Monopolar Microstrip Patch Antenna with Shorting Vias and Coupled Ring. IEEE Antennas Wireless Propag. Lett. 2014, 13, 39-42. [CrossRef]

16. Caloz, C.; Itoh, T. Electromagnetic Metamaterials; Wiley: New York, NY, USA, 2006.

17. Lai, A.; Leong, K.M.K.H.; Itoh, T. Infinite Wavelength Resonant Antennas with Monopolar Radiation Pattern Based on Periodic Structures. IEEE Trans. Antennas Propag. 2007, 55, 868-876. [CrossRef]

18. Lee, J.-G.; Lee, J.-H. Zeroth Order Resonance Loop Antenna. IEEE Trans. Antennas Propag. 2007, 55, 994-997. [CrossRef]

19. Pyo, S.; Han, S.-M.; Baik, J.-W.; Kim, Y.-S. A Slot-Loaded Composite Right/Left-Handed Transmission Line for a Zeroth-Order Resonant Antenna with Improved Efficiency. IEEE Trans. Microw. Theory Tech. 2009, 57, 2775-2782. [CrossRef]

20. Sievenpiper, D.; Zhang, L.; Broas, R.F.J.; Alexopolous, N.G.; Yablonovitch, E. High-Impedance Electromagnetic Surfaces with a Forbidden Frequency Band. IEEE Trans. Microw. Theory Tech. 1999, 47, 2059-2074. [CrossRef]

21. Moosazadeh, M.; Ghobadi, C.; Esmati, Z. Monopole Antenna Based on Wrench-Shaped Slot on Circular Disc Patch for UWB Application. Microw. Opt. Technol. Lett. 2011, 53, 1927-1931. [CrossRef]

22. Sedghi, T.; Rafii, V.; Moosazadeh, M. UWB Monopole Antenna with Compact Polygon-Shaped Patch for Portable Devices. Appl. Comput. Electromagn. Soc. J. 2014, 29, 67.

23. Esmati, Z.; Moosazadeh, M. Band-Notched CPW-FED UWB Antenna Using V-shaped Fractal Elements. Microw. Opt. Technol. Lett. 2015, 57, 2533-2536. [CrossRef]

24. Zhu, X.-Q.; Guo, Y.-X.; Wu, W. A Novel Dual-Band Antenna for Wireless Communication Applications. IEEE Antennas Wireless Propag. Lett. 2016, 15, 516-519. [CrossRef]

25. Nguyen-Trong, N.; Piotrowski, A.; Kaufmann, T.; Fumeaux, C. Low-Profile Wideband Monopolar UHF Antennas for Integration onto Vehicles and Helmets. IEEE Trans. Antennas Propag. 2016, 64, 2562-2568. [CrossRef]

26. Wang, S.; Zhu, L.; Wang, J.; Wu, W. Three-Dimensional Circular Patch Antenna Under TM 02 Mode with Improved Impedance Matching. Electron. Lett. 2019, 55, 169-170. [CrossRef]

(C) 2019 by the authors. Licensee MDPI, Basel, Switzerland. This article is an open access article distributed under the terms and conditions of the Creative Commons Attribution (CC BY) license (http://creativecommons.org/licenses/by/4.0/). 